\title{
Genomics in the Big Apple
}

\section{By Tim Fulmer, Senior Writer}

The New York Genome Center launched its translational research unit last week with the appointment of Robert Darnell as president and scientific director of the center. With the sequencing service side of the center already up and running, Darnell will oversee the development of specific internal research projects as well as the hiring of researchers to fill out the unit.

Late last year, 11 New York City-area medical centers along with industry partners Roche and Illumina Inc. launched the New York Genome Center (NYGC) as a large-scale genome-sequencing facility for translational research.

The basic mission of NYGC is to offer next-generation genome sequencing, bioinformatics services and data storage to researchers worldwide and to set up an in-house translational research center staffed by researchers drawn from local universities and medical institutions.

Darnell will remain professor of cancer biology at The Rockefeller University, one of the founding institutions of NYGC. The other founding institutions include Cold Spring Harbor Laboratory, Columbia University, Cornell University, the Memorial Sloan-Kettering Cancer Center, the Mount Sinai Medical Center, New York-Presbyterian Hospital, New York University, the North Shore-LIJ Health System, The Jackson Laboratory and the State University of New York at Stony Brook. The in-house research center will be located in a permanent facility now being built in Manhattan.

Darnell's research is focused on paraneoplastic neurological disorders (PNDs), which arise when a cancer patient's antitumor response triggers an autoimmune attack on healthy neurological tissue. The protein antigens shared by the tumor and healthy neurons bind and regulate RNA. He has developed methods to generate a genomewide picture of RNA expression and regulation.

Darnell said joining NYGC will allow him and other researchers "to overcome the rate-limiting step of handling and making sense of massive genomics data sets collected across many labs and patient groups."

He added, "NYGC exists to break down traditional research silos.
It will bring together clinicians, genomics researchers, computational modelers and mathematicians under one roof, allowing them to pool, analyze, mine and interpret genomics data in new ways."

NYGC plans to hire at least six principal investigators in the next five years, Executive Director Nancy Kelley told SciBX.

A key goal of the center's research will be to generate new IP covering therapeutics and diagnostics that are made available for licensing, said Kelley. She declined to provide additional details.

"We are recruiting scientists in the general areas of genomics research, clinical biology, bioinformatics and computational biology," Darnell said. "We anticipate having a mix of established and junior researchers on our staff, and researchers will be given the option of maintaining a joint appointment with NYGC and their home academic institution."

Over the next few months, NYGC will make announcements regarding specific research projects to be carried out in the center. "Cancer, neurological diseases and immunology will be three areas of focus," said Darnell. He declined to provide additional details.

NYGC is part of a larger push to make the greater New York City area into a biopharma research hub.

Earlier this year, Laurie Glimcher told SciBX, "New York City has the potential to be a major player in this area." At that time, Glimcher had just been hired as dean of Weill Cornell Medical College. Prior to that, she was a professor at Harvard Medical School.

Weill Cornell, Rockefeller University and Memorial Sloan-Kettering have a tri-institutional alliance and over the past 3 years have together founded 14 biopharma companies. More than half of those are based in New York City. ${ }^{1}$

Fulmer, T. SciBX 5(47); doi:10.1038/scibx.2012.1224

Published online Dec. 6, 2012

\section{REFERENCES}

1. Kotz, J. SciBX 5(2); doi:10.1038/scibx.2012.31

\section{COMPANIES AND INSTITUTIONS MENTIONED}

Cold Spring Harbor Laboratory, Cold Spring Harbor, N.Y.

Columbia University, New York, N.Y.

Cornell University, Ithaca, N.Y.

Harvard Medical School, Boston, Mass.

Illumina Inc. (NASDAQ:ILMN), San Diego, Calif.

The Jackson Laboratory, Bar Harbor, Maine

Memorial Sloan-Kettering Cancer Center, New York, N.Y.

Mount Sinai Medical Center, New York, N.Y.

New York Genome Center, New York, N.Y.

New York-Presbyterian Hospital, New York, N.Y.

New York University, New York, N.Y.

North Shore-LIJ Health System, Manhasset, N.Y.

Roche (SIX:ROG; OTCQX:RHHBY), Basel, Switzerland

The Rockefeller University, New York, N.Y.

State University of New York at Stony Brook, Stony Brook, N.Y.

Weill Cornell Medical College, New York, N.Y. 